\title{
Dios conocido y desconocido en S. Agustín
}

\author{
"Deus ubique secretus est, ubique publicus; quem nulli \\ licet ut est, cognoscere, et quem nemo permittitur igno- \\ rare". \\ Enarr 749 \\ "Quaesivi Deum meum, ut si possem non tantum cre- \\ derem, sed aliquid et viderem". \\ Enarr 417
}

\section{INTRODUCCION}

El pensamiento de San Agustín acerca del conocimiento de Dios por parte del hombre se expresa en dos afirmaciones aparentemente contrarias: Dios es el ser más conocido, Dios es el ser más desconocido.

Las dos afirmaciones son consecuencia lógica de la intuición fundamental del pensamientío platónico-agustiniano: la participación.

Los seres que no son el Ser, participan del Ser. Hay una participación óntica: los seres son porque participan del Ser. Y hay una participación lógica: el espiritu conoce la verdad, porque participa de la Verdad (iluminación). Por un lado los seres participan del Principio y por tanto le son semejantes. Por otro lado el espiritu conoce ese Principio, ese Modelo que participan e imitan los seres.

Primera consecuencia: si todo es semejante a Dios, todo nos da a conocer a Dios y Dios es lo más conocido para el hombre. Segunda consecuencia: si los seres sólo son semejantes a Dios, si sólo son participaciones de Dios, nunca nos darán a conocer el verdadero ser de Dios y Dios es lo más desconocido para el hombre.

Porque los seres participan de Dios, podemos conocerle (hay una semejanza) y no podemos conocerle (el Ser verdadero es totalmente- distinto del ser por participación). 


\section{DIOS CONOCIDO}

\section{De los seres al Ser}

Los seres nos dan a conocer el Ser. A partir de los seres que participan del Ser y por tanto le son semejantes podemos llegar a conocer el Ser verdadero. Esta es una primera fuente de conocimiento de Dios, en San Agustín.

"Vox quaedam est mutae terrae species terrae. Attendis et vides eius speciem... Cum autem inquisieris admirans, et perscrutatus fueris, et magnam vim, magnam pulchritudinem praeclaramque virtutem inveneris, quoniam apud se et a se habere hanc virtutem non posset, continuo tibi venit in mentem quia non potuit a se esse, nisi ab illo Creatore... Nonne considerata universa pulchritudine mundi huius tamquam una voce tibi species ipsa respondet: non me ego feci sed Deus?" 1 .

"Ecce sunt caelum et terra, clamant quod facta sint; mutantur enim atque variantur... Tu ergo, Domine, fecisti ea, qui pulcher es, pulchra sunt enim; qui bonus es, bona sunt enim; qui es, sunt enim. Nec ita pulchra sunt nec ita bona sunt nec ita sunt, sicut tu conditor eorum, quo comparato nec pulchra sunt nec bona sunt nec sunt"' 2.

De un modo especial el espíritu, imagen de Dios, es fuente de conocimiento de Dios. Los libros VII a XIV de la obra De Trinitate buscan precisamente conseguir alguna inteligencia del ser trinitario de Dios a través de su imagen que es el hombre. $Y$ en general el conocimiento de nuestro espíritu es un medio privilegiado para conocer a Dios, que se nos aparece entonces como semejante y superior a nuestra mente.

"Quo intellectu Deum capit homo, qui ipsum intellectum suum quo eum vult capere nondum capit? Si autem hunc iam capit, attendat diligenter nihil eo esse in sua natura melius... Quod ergo non invenimus in meliore nostro non debemus in illo quaerere, quod longe melius est meliore nostro: ut sic intelligamus Deum, si possumus, quantum possumus, sine qualitate bonum, sine quantitate magnum, sine indigentia creatorem, sine situ praesidentem, sine habitu omnia continentem, sine loco ubique totum, sine tempore sempiternum, sine ulla sui mutatione mutabilia facientem, nihilque patientem. Quisquis Deum ita cogitat, etsi nondum potest omni modo invenire quid sit, pie tamen cavet, quantum potest, aliquid de eo sentire quod non sit" 3 .

1. Enar., 14413.

2. Conf XI 6. Cf. Conf X 8-10.

3. Trin V 2. Cf. Trin XIV 6 y 11 . 
El conocimiento que alcanzamos de Dios a través y a partir de los seres por él creados no se limita a su existencia, alcanza también de algún modo a su esencia. No sólo sabemos que Dios es, sino también, en algún modo, qué es.

Sin embargo el pensamiento más característico de San Agustín hay que buscarlo, no en su afirmación de que los seres nos dan a conocer el Ser, sino en su afirmación de que los seres nos dan a conocer que ya conociamos el Ser.

La prueba "agustiniana" de la existencia de Dios no busca la razón suficiente de la existencia de los seres, sino la razón suficiente del conocimiento del Ser que hay en el espíritu. En un mundo de seres mudables, el espíritu, mudable también, conoce lo inmutable; en un mundo de entes, el espíritu, ente también, conoce el Ser. El espíritu conoce el horizonte absoluto del ser, de la verdad, del bien; conoce la ley incondicionada y a partir de esa ley "juzga" la verdad y el bien de los seres. ¿Cómo explicar este conocimiento del Ser por el espíritu? El conocimiento del Ser por el hombre sólo puede tener su origen en el mismo Ser. Sólo la existencia del Ser puede explicar y fundar el conocimiento del Ser en el espíritu finito.

Este es el sentido de todas las "ascersiones" agustinianas, que buscan el Ser a partir de los seres, que buscan lo inmutable a partir de lo mudable, que buscan el fundamento a partir de lo dado. ¿Cómo podrían buscarlo si no lo conocieran? ¿Y cómo podrían reconocerlo si no 10 preconocieran?".

\section{Del Ser a los seres}

Los seres que no son el Ser (porque cambian), participan del Ser y le son semejantes, y por tanto nos dan a conocer de algún modo el Ser. Las copias nos dan a conocer el Modelo.

Pero lo contrario es aún más verdadero, en el pensamiento de San Agustín. No podríamos reconocer el ser, la verdad, el bien de los seres, si antes no (pre) conociéramos el Ser, la Verdad y el Bien. El conocimiento del Modelo nos permite reconocer las copias. Bene probat imaginem quisquis eius intuetur exemplum 5 .

4. Cf. Conf X 8-38; Enarr 41 7-8, etc.

5. CAcad III 40. 
No somos sabios (saplientes), pero conocemos (y amamos) la sabiduria: sapientiae notionem in mente habemus impressam ${ }^{6}$. No somos felices (beati), pero conocemos (y amamos) la felicidad: mentibus nostris impressa est notio beatitudinis ${ }^{7}$. No somos justos, pero conocemos (y amamos) la justicia, impresa en nuestros corazones ${ }^{8}$.

En una palabra, somos entes, en un mundo de entes, pero conocemos el Ser: de otro modo no podríamos reconocer y afirmar el ser de los entes. Somos mudables en un mundo mudable, pero conocemos la verdad inmutable: de otro modo no "juzgariamos" incondicionadamente de la verdad y el error.

Esta es la profunda intuición platónico-agustiniana. Dios es, para el hombre, primum notum. En el espíritu finito, a todo conocimiento personal de verdad y a todo amor personal de bien precede, como su condición de posibilidad, un conocimiento y un amor naturales de la Verdad y del Bien, del Ser verdadero.

Porque preconocemos la Veritas, podemos reconocer y afirmar el verum. Porque preamamos la Bonitas, podemos amar el bonum. Porque preconocemos el Ser verdadero podemos reconocer los seres por participación. Porque preconocemos la ley (necesaria; inmutable), podemos "juzgar" de los hechos, de la empiría contingente y temporal.

El conocimiento de Dios es, para el hombre, anterior al conocimiento de sí mismo. Para poder afirmar: yo soy, antes he de conocer el Ser. Si no conozco el horizonte del ser y la verdad absolutos $_{y}$ necesarios, ¿cómo voy a afirmar absoluta y necesariamente que soy? El cogito ergo sum, de Descartes, no es una verdad primera, sino derivada. El principio último, radical, es el preconocimiento (y prevolición) del Ser, de la Verdad y del Bien ${ }^{9}$.

Dios es, para el espíritu finito, primum notum. Más aún, el espíritu es constitutivamente conocimiento y amor del Ser verdadero: por esto conoce y por esto ama los seres. Un espíritu sin cono-

\section{LArb. III 26.}

7. Ibidem.

8. Trin VIII 9; XIV 21.

9. Cf. J. Pegueroles, "El fundamento del conocimiento de la verdad, en San Agustín: la 'memoria Dei" en Pensamiento 29 (1973) 5-35. 
cimiento (preconocimiento) del Ser sería tan incomprensible como un cuerpo sin extensión ${ }^{10}$.

Pero hay que hacer aquí una observación importante. El conocimiento del Ser no es una cogitatio en la intelligentia, sino una notitia en la memoria. En otras palabras, no es un conocimiento, no es un concepto, sino un preconocimiento, la condición de posibilidad del concepto.

De manera que, en un primer sentido, el conocimiento de las cosas y el conocimiento de sí mismo es para el hombre antes que el conocimiento de Dios. No sabríamos que conocíamos el Ser, si no conociéramos primero los seres. Pero la primera vez que afirmamos: la rosa es bella, descubrimos que ya conocíamos (preconocíamos) la Belleza, de otro modo nunca la habriamos reconocido. Por tanto, en un segundo sentido, el conocimiento del Ser es antes que el conocimiento de las cosas o de nosotros mismos.

Tiene lugar aquí un renversement. Primero Dios aparece como un punto de llegada, como una construcción del espíritu, que a partir de los seres, negando límites, elabora la idea del Ser. Pero entonces descubrimos que la construcción de la idea de Dios sólo fue posible gracias al preconocimiento de Dios presente en el espíritu. ¿Cómo explicar, si no, esta necesidad que hay en el espíritu finito de trascender todo límite y toda multiplicidad y llegar hasta la omnitudo realitatis? ${ }^{11}$.

Del mismo modo, la idea abstracta de Ser es posterior y derivada del conocimiento de los entes. Pero sólo el preconocimiento del Ser hizo posible reconocer el ser de los entes y elaborar por abstracción la idea general de Ser.

10. Cf. J. Pegueroles, "La conversión de la materia a la forma", en Espiritu 23 (1974) 53-65. En especial cf. p. 62.

11. Ci. J. Moreau, Le Dieu des philosophes (Paris, 1969), cap. 9. 


\section{DIOS DESCONOCIDO}

\section{El Ser es incomprensible}

El preconocimiento de Dios en la memoria no puede tematizarse, objetivarse. Es una presencia, condición de posibilidad de la representación, pero ella misma no puede ser objetivada en la representación. Por tanto no implica un conocimiento de la esencia de Dios. Implica solamente una capacidad de negación de lo que no es Dios. "L'abstrusior profunditas nostrae memoriae ne communique à la pensée aucune connaissance positive de l'Etrë divin. Elle lui donne cependant un critère négatif très sûr pour juger tout ce qui pourra être dit au sujet de Dieu"12.

La segunda afirmación del pensamiento agustiniano acerca del conocimiento de Dios dice que Dios es el ser que menos conocemos. $Y$ deriva lógicamente, como quedó indicado, lo mismo que la primera, de la teoría platónica de la participación.

El Ser es totalmente distinto de los seres. Los seres no pueden darnos a conocer el Ser.

Los seres que conocemos no son el Ser, tienen ser; no son la Verdad, tienen verdad; no son el Bien, tiene bondad. Pero Dios quod habet hoc est, es lo que tiene ${ }^{13}$. Por tanto no puede el hombre representarse ese Ser, que no participa del Ser, de la Verdad, del Bien, sino que es el Ser, la Verdad y el Bien.

"Sententia catholicae disciplinae... aliud dicit bonum quod summe ac per se bonum est et non participatione alicuius boni, sed propria natura et essentia; aliud quod participando bonum et habendo; habet autem de illo summo bono ut bonum sit, in se tamen manente illo nihilque amittente" ${ }^{14}$.

"Non participatione magnitudinis Deus magnus est, sed se ipso magnus est, quia ipse sua est magnitudo. Hoc et de bonitate et de aeternitate et de omnipotentia dictum sit" ${ }^{15}$.

Los seres que conocemos no son, devienen. Son mudables, temporales. Tienen su ser desparramado por el tiempo. Son y no

12. V. Losskx, "Eléments de 'théologie négative' chez saint Augustin", en Augustinus Magister (Paris, 1954), vol. I, p. 578.

13. Ioan 48 6. Cf. Civ Dei XI 2-3.

14. Mor Man 6.

15. Trin V 11. 
son. Ya no son lo que eran, todavía no son lo que serán. Por tanto no puede el hombre comprender a Dios inmutable, al Ser que ES.

"Hoc maxime esse dicendum est quod semper eodem modo sese habet, quod omnimodo sui simile est, quod nulla ex parte corrumpi ac mutari potest, quod non subiacet tempori, quod aliter nunc se habere quam habebat antea non potest. Id enim est quod esse verissime dicitur. Subest enim huic verbo manentis in se atque incommutabiliter sese habentis naturae significatio" 16

Los seres que conocemos son esto o lo otro. Son la flor, son el pájaro, son la montaña o el mar. Tienen una forma de ser y una medida de ser. Por tanto no puede el hombre comprender a Dios, que no es nada (ni esto ni aquello), que es sin forma ni medida ${ }^{17}$.

Son conocidos los textos en que San Agustín afirma vigorosa. mente la incomprensibilidad de Dios.

"Deus ineffabilis est. Facilius dicimus quid non sit quam quid sit. Terram cogitas, non est hoc Deus; mare cogitas, non est hoc Deus..." 17 bis.

"De Deo loquimur, quid mirum si non comprehendis? Si enim comprehendis non est Deus" 18 .

"Quid ergo dicamus, fratres, de Deo?... Si comprehendere potuisti, aliud pro Deo comprehendisti. Si quasi comprehendere potuisti, cogitatione tua te decepisti. Hoc ergo non est, si comprehendisti; si autem hoc est, non comprehendisti" 19.

Quien cree conocer a Dios no le conoce, está conociendo otra cosa en lugar de Dios. El conocimiento más alto que podemos alcanzar de Dios es conocer que supera todo conocimiento.

"Amet non inveniendo invenire potius quam inveniendo non invenire te" 20 .

\section{El Incomprensible es Ser}

Dentro de la tradición mística cristiana, especialmente en los Padres griegos, la afirmación de la incomprensibilidad de Dios pa-

16. Mor Man 1.

17. O bien que es "mensura sine mensura". Gen litt IV 7.

17.bis Enarr 8512.

18. Sermo $117 \cdot 5$.

19. Sermo 5216 .

20. Conf I 10. 
rece rozar en ocasiones el agnosticismo, debido a la acusada influencia del pensamiento de Plotino.

La filosofía griega, en general, es una filosofía de la forma, de la esencia. Ser es ser-bueno o ser-uno... Una filosofía de la forma o de la esencia es una filosofía de la finitud, concibe necesariamente el Ser como finito. Para esa filosofía, la infinitud no es una perfección, es una deficiencia. Infinito es lo que no tiene forma, lo informe, lo imperfecto, lo inacabado.

Plotino parece ser el primero que intenta romper el cerco de la forma y atisba la infinitud del Ser como positividad. Sigue admitiendo la ecuación platónica: ser = forma. Pero afirma que hay un más allá del ser: la Unidad o el Uno. El principio es uno, pero no es ser, por tanto no es forma, por tanto no está limitado por la esencia, por tanto es infinito. La región del ser empieza en la Inteligencia, que contiene las ideas o formas de las cosas. Los seres no participan del Uno (que no es ser), sino de la Inteligencia, sede de las formas de ser.

Los pensadores cristianos, al asumir el pensamiento plotiniano, identificarán el Uno con el Padre y la Inteligencia con el Verbo Pero tendrán que hacer frente a un doble peligro. El peligro de un subordinacionismo en teología, es decir, de hacer al Verbo inferior al Padre. $Y$ el peligro de agnosticismo en lo tocante al conocimiento de Dios ${ }^{21}$.

En efecto, si por un lado Dios no es ser (forma), sino que está más allá del ser; y por otro lado el entendimiento humano sólo puede conocer el ser, la forma, la idea: se sigue que el hombre no puede conocer a Dios ${ }^{22}$.

San Agustín es, en este punto, más platónico que plotiniano, y evita el agnosticismo sin atentar a la incomprensibilidad de Dios. Donde Plotino decía: los seres son mudables, luego el Uno inmutable no es ser; San Agustín dirá: los seres son mudables, luego no son el Ser, sólo lo inmutable es verdadero Ser.

La afirmación es antes que la negación. Toda negación supone una afirmación. Cuando negamos conocer qué es Dios, algo co-

21. Cf. V. LosskY, o. c., pp. 375 ss.

22. En el De ordine (386), hallamos ecos de esta concepción: "De summo illo Deo, qui scitur melius nesciendo" (II 44). "Cuius (Dei) nulla scientia est in anima, nisi scire quomodo eum nesciat" (II 47). 
nocemos de Dios, para poder afirmar que no podemos conocerle, que supera todo conocimiento y todo ser creado. No es poco conocimiento de Dios, repite San Agustín, conocer lo que Dios no es.

"Non parva est inchoatio cognitionis Dei, si antequam possimus nosse quid sit, incipiamus iam nosse quid non sit" ${ }^{23}$.

"Non parvae notitiae pars est..., si antequam scire possimus quid sit Deus, possimus iam scire quid non sit" ${ }^{24}$.

"Sic sunt incomprehensibilia requirenda, ne se existimet nihil invenisse, qui quam sit incomprehensibile quod quaerebat potuit invenire", 25 .

Dios es inefable, pero al afirmarlo así, negamos que lo sea del todo, podemos "decir" a Dios de algún modo.

"Diximusne alíquid et sonuimus aliquid dignum Deo? Imo vero nihil me aliud quam dicere voluisse sentio; si autem dixi, non hoc est quod dicere volui. Hoc unde scio, nisi quia Deus ineffabilis est; quod autem a me dictum est, si ineffabile esset, dictum non esset? Ac per hoc ne ineffabilis quidem dicendus est Deus, quia et hoc cum dicitur, aliquid dicitur. Et fit nescio quae pugna verborum, quoniam si illud est ineffabile quod dici non potest, non est ineffabile quod vel ineffabile dici potest" ${ }^{26}$.

Afirmar que no conocemos qué es Dios equivale a afirmar que algo conocemos del ser de Dios: negativamente, que no podemos conocerle; positivamente, que trasciende todo conocimiento finito.

"Cum ille unus cogitatur deorum Deus..., ita cogitatur, ut aliquid quo nihil melius sit atque sublimius illa cogitatio conetur attingere" 27 .

"Illud summum bonum quo non est quidquam melius aut superius" ${ }^{28}$.

Por esto San Agustín, en una expresión célebre, ha calificado nuestro desconocimiento de la eternidad y de Dios, de docta ignorantia:

"Quod sicuti est cogitare non possumus utique nescimus; sed quidquid cogitanti occurrerit abicimus, respuimus, improbamus, non hoc esse quod quaerimus novimus, quamvis illud nondum quale sit noverimus. Est ergo in nobis quaedam, ut ita dicam, docta ignorantia..." 2 .

23. Epist 12013.

24. Trin VIII 3.

25. Trin XV 2.

26. Doc crist I 6.

27. Doc crist I 7

28. Mor Man 1.

29. Epist 130 27-28. 


\title{
III. LAS FUENTES DEL CONOCIMIENTO DE DIOS
}

De Dios podemos conocer qué es, su existencia, requerida como único fundamento posible del conocimiento del Ser que hay en el espíritu.

De Dios no podemos conocer qué es, su esencia. Dios es incomprensible para el hombre. Pero esta negación de conocimiento implica algún conocimiento. Conocemos algo de Dios cuando decimos que no podemos conocerle.

Supuesta esta doble afirmación, que conocemos la existencia de Dios y que desconocemos su esencia, cabe preguntar con San Agusín: ¿podemos alcanzar algún conocimiento positivo de la esencia de Dios? Sí, por tres caminos: por la fe, por la razón teórica y por la razón práctica.

\section{La fe}

La existencia de Dios es, según San Agustín, una verdad evidente para todos y reconocida prácticamente por todos.

\begin{abstract}
"Haec est vis verae divinitatis ut creaturae rationali iam ratione utenti non omnino ac penitus possit abscondi. Exceptis enim paucis in quibus natura nimium depravata est, universum genus humanum mundi huius fatetur auctorem" ${ }^{29}$ bis.

Pero es muy difícil llegar a conocer la verdadera naturaleza del ser de Dios ${ }^{30}$. Son muy pocos los que alcanzaron a vislumbrarla, sólo algunos grandes filósofos ${ }^{30}$ bis. Por esto Dios mismo se ha
\end{abstract}

29 bis Ioan 1064 .

30. "Illi in vos saeviant, qui nesciunt cum quo labore verum inveniatur, et quam difficile caveantur errores. Illi in vos saeviant, qui nesciunt quam rarum et arduum sit carnalia phantasmata piae mentis serenitate superare. Illi in vos saeviant, qui nesciunt cum quanta difficultate sanetur oculus interioris hominis, ut possit intueri solem suum... Illi in vos saeviant, qui nesciunt quibus suspirils et gemitibus fiat, ut ex quantulacumque parte possit intelligi Deus. Postremo, illi in vos saeviant, qui nunquam tali errore decepti sunt, quali vos deceptos vident". Contra epist. fund. 2.

30 bis. Esos filósofos son los neoplatónicos, que vieron en Dios al inmutable, al id quod est, al ipsum esse. Conocieron a Dios, pero, cegados por la superbia, no le dieron gracias. Alcanzaron a ver de lejos la patria, pero no supieron dar con el camino. Les faltaba la necesarla mediación de Jesucristo. Cf. G. MADEC, "Connaissance de Dieu et action de grâces", en Recherches Augustiniennes, vol. II, 1962, pp. 273-309. 
Ievelado en Cristo y ahora todos los hombres, grandes o pequeños, tienen acceso, por la fe cristiana, a un conocimiento oscuro, pero verdadero, del ser de Dios.

"Magnum est et admodum rarum universam creaturam corpoream et incorpoream consideratam compertamque mutabilem intentione mentis excedere, atque ad incommutabilem Dei substantiam pervenire, et illic discere ex ipso, quod cunctam naturam quae non est quod ipse non fecit nisi ipse... Ut fidentius ambularet ad veritatem, ipsa veritas Deus Dei filius homine assumpto, non Deo consumpto, eamdem constituit atque fundavit fidem, ut ad hominis Deum iter esset homini per hominem Deum" ${ }^{31}$.

Cuando San Agustín comienza a escribir su gran tratado sobre la Trinidad, recuerda ante todo la necesidad de partir de la fe.

"Substantiam Dei sine ulla sui commutatione mutabilia facientem, et sine ullo suo temporali motu temporalia creantem, intueri et plene nosse difficile est: et ideo est necessaria purgatio mentis nostrae, qua illud ineffabile ineffabiliter videri possit" 32 .

Las tres fuentes del conocimiento de Dios, los tres caminos para responder a la pregunta ¿qué es Dios?, son a la vez, en el pensamiento agustiniano, tres niveles ascendentes de conocimiento. En el primero, creemos que Dios es inmutable, que Dios es el Ser. En el segundo, la razón por analogía a través de lo creado alcanza algún conocimiento, alguna ciencia del Ser de Dios. En el tercero, el hombre, por el amor (caritas), conoce (videt) a Dios, pero de un modo inefable; siente (sentit) a Dios, pero no puede expresar lo que siente; toca (attingit) a Dios, pero no puede comprenderlo (o abarcarlo) ${ }^{33}$.

\section{La razón teórica: La analogía}

Dos son los errores que quiere evitar San Agustín al tratar del conocimiento de Dios: "Croire que rien de ce que l'on sait des choses ne peut en aucun sens être affirmé de Dieu, et croire que ce que

31. Civ Dei XI 2.

32. Trin I 3 .

33. "Attingere aliquantum mente Deum magna beatitudo est; comprehendere autem, omnino impossibile". Sermo 1175. 
l'on sait des choses peut être affirmé de Dieu dans le même sens qu'on l'affirme des choses" ${ }^{34}$.

En general, todo puede decirse de Dios y nada puede decirse dignamente de El

"Omnia possunt dici de Deo, et nihil digne dicitur de Deo. Nihil latius hac inopia. Quaeris congruum nomen, non invenis; quaeris quoquo modo dicere, omnia invenis" 35 .

También en general, enuncia San Agustín que nuestro conocimiento de Dios trasciende nuestras palabras y que el ser de Dios trasciende nuestro conocimiento: verius cogitatur Deus quam dicitur, et verius est quam cogitatur ${ }^{36}$.

Más en concreto, enunciará San Agustín que nuestros conceptos y palabras pueden aplicarse a Dios, pero sólo bajo ciertas condiciones. El texto más importante es la respuesta a la segunda quaestio de Simpliciano. En ella formula, en otros términos, la misma distinción de Santo Tomás entre la res significata y el modus significandis ${ }^{37}$.

La pregunta era: ¿cómo puede Dios arrepentirse, si lo sabe todo de antemano? La presciencia nos parece digna de Dios, el arrepentimiento, no, es una imperfección. Responde San Agustín: todo concepto, toda palabra humanos son indignos de Dios.

"Ego vero, cum hoc de Deo dicitur, indignum aliquid dici arbitrarer, si aliquid dignum inveniretur quod de illo diceretur ${ }^{38}$.

La presciencia es conocimiento del futuro. Pero para Dios no hay futuro, no hay tiempo. Luego la presciencia de Dios trasciende nuestro concepto de la misma: invenerit huius etiam verbi notionem illius ineffabili divinitate longe lateque superari ${ }^{39}$.

Sin embargo, esos mismos conceptos y palabras con que designamos las realidades humanas y mundanas pueden legítimamen-

34. E. Gilson, Introduction à l'étude de saint Augustin (Paris, 1929), p. 280 .

35. Ioan 135 .

36. Trin VII 7

37. H. LYTTKENS, The analogy between God and the world (Uppsala, 1953), p. 120.

38. De div quàest ad Simpl II 1.

39. O. c. II 2. 
te aplicarse a Dios, pueden darnos algún conocimiento del ser de Dios.

"Ostenditur multa divina iisdem nominibus appellari quibus humana, cum incomparabili diversitate seiuncta sint. Nec tamen frustra eadem sunt rebus utrisque indita vocabula, nisi quia haec cognita quae in cotidiana consuetudine versantur, et experimentis usitatioribus innotescunt, nonnullam ad intelligenda illa sublimia praebent viam" ${ }^{40}$.

El concepto de ciencia, por ejemplo, si prescindimos del modo como se da en el hombre, si trascendemos su limitación, su mutabilidad, podrá ser aplicado a Dios con algún sentido (insinuare).

"Cum enim dempsero de humana scientia mutabilitatem, et transitus quosdam a cogitatione ad cogitationem, cum recolimus, ut cernamus animo, quod in contuitu eius paulo ante non erat, atque ita de parte in partem crebris recordationibus transilimus...; cum ergo haec omnia detraxero, et reliquero solam vivacitatem certae atque inconcussae veritatis; imo non reliquero, non enim habet hoc humana scientia, sed pro viribus cogitavero, insinuatur mihi utcumque scientia Dei, quod tamen, ex eo quod sciendo aliquid non latet hominem, potuit esse rei utrique commune" ${ }^{41}$.

En resumen, hay ciencia en Dios, hay presciencia, pero de un modo totalmente distinto que en el hombre: et scit Deus et praes. cit Deus ineffabili modo ${ }^{42}$.

\section{La razón práctica: el amor}

No es poco conocimiento de Dios saber lo que Dios no es, repite una vez más San Agustín.

"Si non potestis comprehendere quid sit Deus, vel hoc comprehendite quid non sit Deus: multum profeceritis si non aliud quam est de Deo senseritis. Nondum potes pervenire ad quid sit, perveni ad quid non sit... Si non vales comprehendere Deus quid sit, parum non tibi putes esse scire quid non sit" ${ }^{43}$.

Pero en ocasiones San Agustín se pregunta: ¿y cómo podríamos llegar a saber qué es Dios? Loquor vobis quid non sit Deus,

40. O. c. II 3.

41. O. c. II 3.

42. O. c. II 2. Cf. Contra Adim man 4 y 11; Contra adv legis I 40; sermo $3419 ;$ Trin 7-9.

43. Ioan $239-10$. 
non ostendo quid sit: ergo ut capiamus quid sit, quid faciemus? ${ }^{44}$. $Y$ responde que hay una manera de conocer a Dios como El es: hacernos semejantes a Dios por el amor.

Citando a Plotino, advierte San Agustín que la cercanía o lejanía del espíritu respecto de Dios no es espacial, sino moral. ¿Qué es acercarse a Dios? Similem Deo fieri. Cuando nos asemejamos a Dios nos acercamos a El. Nos alejamos por la desemejanza. Y la semejanza o desemejanza son obra del amor.

"Si Deo quanto similior, tanto fit quisque propinquior; nulla est ab illo alia longinquitas quam eius dissimilitudo" 45

"Ut non sit longe (Deus), et ut longe sit, tu facis. Ama et propinquabit; ama et habitabit" ${ }^{45}$.

Por otro lado, sólo lo semejante conoce a lo semejante. San Agustín conocia sin duda el texto de Plotino: "Es necesario ante todo que el ojo que ve se haga afín y parecido al objeto visto en beneficio de la contemplación. Jamás un ojo vería el sol de no haberse hecho de alguna manera semejante al sol, ni un alma vería lo bello si ella misma no se hiciese bella. Que todo se haga pues en primer lugar semejante a Dios y bello, si quiere contemplar a Dios y a lo Bello" 47 .

Pues bien, la medida del conocimiento de Dios, afirma San Agustín, es la semejanza de Dios en el espíritu. $Y$ esta semejanza es obra del amor.

\begin{abstract}
"In tantum videbimus, in quantum similes ei erimus; quia et nunc in tantum non videmus, in quantum dissimiles sumus. Inde igitur videmus, unde similes erimus... Et tanto efficimur similiores illi, quanto magis in eius cognitione et caritate proficimus" ${ }^{48}$.
\end{abstract}

En otro texto, afirma primero San Agustín que la cercanía o lejanía respecto de Dios consiste en la semejanza o desemejanza: dissimilis factus, longe recessisti; similis factus, proxime accedis ${ }^{49}$.

44. Ioan 2311

45. Civ Dei IX 17. Ya Platón había enseñado: "Hemos de procurar huir lo antes posible de esta morada a la de los dioses. Esta huida consiste en nuestra semejanza con Dios". Teeteto 176 a.

46. Sermo 212.

47. Enéada I VI 9.

48. Epist 923.

49. Enarr 995 
Establece después que la semejanza o desemejanza es moral y consiste en el amor. El amor (caritas) nos hace semejantes y entonces conocemos a Dios, mejor dicho, le sentimos.

\begin{abstract}
"Quantum accedis ad similitudinem, tantum proficis in caritate, et tanto incipis sentire Deum... Ea quae facta sunt intuere, mirare, quaere auctorem. Si dissimilis sis, repelleris; si similis, exsultabis. Et cum accedere coeperis similis, et persentiscere Deum, quantum in te charitas crescit, quia et caritas Deus est, senties quiddam quod dicebas et non dicebas. Ante enim quam sentires, dicere te putabas Deum; incipis sentire, et ibi sentis dici non posse quod sentis" 50 .
\end{abstract}

Sentimos a Dios, sin poder expresar en conceptos o palabras adecuadas lo que sentimos. Pero a veces San Agustín, ya en el plano de la teología, indica que algo podemos expresar del mismo ser de Dios: que es caridad.

"Putas quid est Deus? Putas qualis est Deus? Quidquid finxeris non est, quidquid cogitatione comprehenderis non est. Si enim ipse esset, cogitatione comprehendi non posset. Sed ut aliquid gustu accipias: Deus caritas est" ${ }^{51}$.

Est quod cogites si vis videre Deum: Deus dilectio est" ${ }^{52}$.

Sabemos bien qué es el amor (humano). Todo el que ama, conoce el amor. Del mismo modo, todo el que ama con amor sobrenatural (caritas), conoce por experiencia la caridad, y conoce a Dios que es caridad.

"Potes mihi dicere: non vidi Deum. Numquid potes mihi dicere: non vidi hominem? Dilige fratrem. Si enim fratrem quem vides dilexeris, simul videbis et Deum, quia videbis ipsam caritatem, et intus habitat Deus" ${ }_{53}$.

\title{
Final
}

Cerraré este trabajo con un texto notable, que resume en pocas líneas las dos tesis agustinianas: que Dios es para el hombre lo más desconocido y lo más conocido.

50. Enarr 995 y 6.

51. Sermo 212.

52. Epist Ioan VII 10.

53. Epist Ioan V 7. Cf. Trin VIII 10-12. 
Primera tesis. El hombre, espiritu en el mundo, conoce sólo los seres temporales, y no puede conocer el Ser inmutable, y por ello inefable.

"Illa aeterna incommutabilisque natura, quod, Deus est, (habet) in se ut sit..., longe scilicet aliter quam sunt ista quae facta sunt. Quoniam illud vere ac primitus est quod eodem modo semper est, nec solum non commutatur, sed commutari omnino non potest; nihil horum quae fecit existens, et omnia primitus habens, sicut ipse est... Illa substantia ineffabilis (est) nec dici utcumque homini per hominem (potest), nisi usurpatis quibusdam locorum ac temporum verbis, cum sit ante omnia tempora et ante omnes locos".

Segunda tesis. Es más fácil conocer a Dios que a los seres corporales. Dios está más cerca de nosotros. Los cuerpos nos son exteriores y extraños. Dios nos es interior y somos imagen suya.

"Propinquior nobis est qui fecit, quam multa quae facta sunt. In illo enim vivimus et movemur et sumus; istorum autem pleraque remota sunt a mente nostra propter dissimilitudinem sui generis, quoniam corporalia sunt... Remota quippe sunt et a sensibus corporis nostri, quoniam longe sunt, vel interpositis aut oppositis aliis a nostro' contuitu tactuque separantur. Ex quo fit ut maior ad illa invenienda sit labor, quam ad illum a quo facta sunt, cum sit imcomparabili felicitate praestantius illum ex quantulacumque particula pia mente sentire, quam illa universa comprehendere" ${ }^{54}$.

Juan Pegueroles, S.J.

54. Gen litt $\mathrm{V} 34$. 